\title{
Using new digital technologies in employee training to avoid occupational accidents in the industry
}

\author{
Petru Iulian Muresan ${ }^{1, *}$, Ioan Milosan ${ }^{1}$, Teodor Machedon-Pisu ${ }^{2}$, Adrian Reit ${ }^{3}$, Dorin \\ Senchetru ${ }^{3}$ and Gheorghe Oancea ${ }^{4}$ \\ ${ }^{1}$ Materials Science Department, Transilvania University of Brasov, 500036, Brasov, Romania \\ ${ }^{2}$ Materials Engineering and Welding Department, Transilvania University of Brasov, 500036, Brasov, \\ Romania \\ ${ }^{3}$ Territorial Labor Inspectorate of Brasov County, 500080 Brasov, Romania \\ ${ }^{4}$ Manufacturing Engineering Department, Transilvania University of Brasov, 500036, Brasov, Romania
}

\begin{abstract}
The most frequent workplace accidents in the industry are most of the times caused by the employer's failure to fulfill their obligation to provide appropriate on-the-job training. Starting from this state of affairs, this paper analyzes the main cause of workplace accidents in the industry, which is the lack of training, or incomplete or inadequate training of employees, a situation indicated by the latest studies and the latest activity report of Labor Inspectorate. The solution identified by most employers was to use the online environment, this being the only way that allows the achievement of both of the aforementioned objectives at the same time. In this context, the paper identifies and proposes the use of the online environment, especially in the process of distance training of workers, giving them the opportunity to receive training documents, to analyze them, to electronically sign them and send them to the employer in electronic format. This proposal of supplementing the current legislation with the possibility of using the online environment in the field of occupational health and safety (OHS) also takes into account other categories of benefits that this solution brings, such as streamlining OHS and optimizing costs incurred in fulfilling these legal obligations.
\end{abstract}

\section{Introduction}

Starting from studies conducted during the past years, taking into account the latest report of the Brasov Territorial Labor Inspectorate 2019 [1] it was clearly found that one of the main causes of accidents is caused by lack of training, insufficient or inadequate training, excessive formalities caused by lack of concern of the main actors in this process. The formalism in the worker training process is caused both by the attitude of the employer who, out of the desire not to interrupt the work activities for the training, skips this process, as well as by the employees who only sign the training sheets and treat the health and safety training phases superficially [2-4]. 
In conclusion, the most frequent workplace accidents occur due to the failure to fulfill the obligation of proper on-the-job training, and the fact that many employers are satisfied to ensure only the signing of training forms formally, without an actual training $[5,6]$.

The situation generated by the COVID-19 pandemic, highlighted the fact that the obligation of employers to take measures to prevent the spread of this virus, a measure that aims mainly at finding ways to carry out activities using work from home, telework and avoid as much as possible the interaction between workers is not possible without using the online environment. In this context, online communication with employees is the only way to allow, at the same time, both compliance with measures to prevent the spread of COVID-19 virus and the implementation of obligations on training in occupational safety and health, which the employer has according to the laws in force.

Compared to the current classic training methods on the proper conduct of occupational safety and health in order to prevent accidents at work, this training method involves the use of online environment, especially in the process of distance training of workers, represents the possibility of training and recording the training, for the validity of the activity, the electronic signature of the documents prepared and sent to the workers in electronic format. In this way, any document drawn up, sent and signed in electronic format covers the requirements imposed by the legislation in force for them to produce the legal effects imposed by Law 319/2006, GD 1425/2006 and other normative acts by which obligations regarding occupational safety and health are set forth.

In case of an event in which the worker is involved while performing their duties, the proof of training the worker is the first issue that will be verified by the authorities, and the impossibility to prove with documents that they have been properly trained is likely to engage contraventional, criminal or civil liability of the employer [7-9].

\section{Case study: digital ohs during the pandemic}

As the risk of COVID-19 infection emerged, the Ministry of Labor and Social Protection (MMPS) of Romania made a series of recommendations in order to ensure the safety and health of workers, but also to support employers in carrying out current activities. These measures aimed to clarify the new situations in which employers and employees may find themselves in terms of employment relations, as a result of emergency measures imposed by the National Committee for Special Emergency Situations.

Aiming to prevent the spread of coronavirus infection, the recommendations of the Ministry of Labor and Social Protection were intended to make employment relations more flexible, thus identifying 3 (three) legal provisions (listed below) that employers can use to carry out the activity, provisions that provided the employers with the possibility to carry out their activity during the pandemic as well.

- Setting individualized work schedules, with the consent or upon the request of the employee in question, in accordance with the provisions of article 118 of Law no. 53/2003Labor Code, republished, with subsequent amendments and completions, in compliance with the maximum legal duration of working time.

- Temporary transfer of the workplace at the employee's home, in accordance with the provisions of article 108-110 of the Labor Code, unilaterally, in accordance with the provisions of article 48 of the same normative act, or by agreement of the parties, explicitly specifying the following elements in the decision or, as the case may be, in the addendum modifying the workplace:

- the fact that the employee works from home;

- the period during which this measure applies;

- the hours during which the employer is entitled to check the activity of their employee and the actual method of carrying out the check; 
- the obligation of the employer to ensure the transport to and from the employee's home, as the case may be, of the raw materials and materials used in the activity, as well as the finished products they produce.

- Performing the activity through teleworking, after the conclusion of an addendum to the individual employment contract, under the conditions provided by Law no. 81/2018 regarding the regulation of the teleworking activity, when the fulfillment of the duties specific to the position, occupation or profession that the employee holds implies the use of information and communications technology.

Two years ago, we initiated the digital OSH project, through which we proposed that the occupational health and safety activity can be managed through digital platforms that can ensure performing the activity remotely in compliance with the legal requirements imposed by the rules in force.

Starting from the fact that the employer has the obligation to ensure the safety and health of workers according to Law no. 319/2006, updated in all of the three situations presented above, the obligation to train the employee subsists regardless of the place where they perform their duties.

In this context, the employers who were the subject of the case study chose the duties assigned to their employees to be carried out from their home. The very rapid succession of measures that had to be taken by employers in the context of the pandemic led to the circumstances in which they had a very short period of time to change the workplace of employees, and at the same time to ensure that the activity in the new workplace will be carried out in compliance with occupational health and safety conditions, an issue that implies the worker training regarding the work that they were to perform from home.

Given that the employer has the obligation to provide proof of the worker training regarding the established duties and that this proof is made by registering the training in the occupational health and safety record, this obligation proved impossible to perform under the conditions established by law, since the fulfillment of this obligation would have meant ignoring the social distancing measures.

In order to fulfill this legal obligation, the employers requested solutions that would allow both the possibility of performing the training and recording it in a document that complies with the necessary legal requirements, so that the resulting document would produce the legal effects imposed by law.

Considering the need for social distancing, the online environment has become the only means of fulfilling the obligation to train workers provided that the IT tools used to ensure both the transmission of information on training and the ability to verify knowledge, an approach that must be recorded in a document that can prove the material based on which the worker was trained, the fact that they acquired the knowledge and, at the same time, this document can allow the possibility of signing it by all those involved in the training process, thus ensuring the existence of a legally valid document.

Taking into consideration the above shown issues and by agreement of those who chose to be the subject of this case study, it was decided that for the training and testing of workers in the online environment, to use the training function of the ssm.ro platform, the platform that allows training, testing the knowledge and recording it in a document on which the electronic signature can be applied as it is defined in the national and European legislation.

The case study included a number of two companies ( $\mathrm{I}$ and $\mathrm{O}$ ) totaling a number of 481 workers who worked at home scattered both in Romania and abroad.

In view of the use of the SSM.ro computer platform in the present study, the following steps were followed:

1. Creating the accounts of the user companies on the platform, specifying all their legal identification data. 
2. Assigning the roles of users on the platform (administrator, employee, occupational health and safety inspector).

3. Generating the organizational chart of a company which reveals the hierarchy in the company.

4. Enrollment of all employees of the companies on the platform, establishing their position, the department to which they belong and the supervisor. For communication and identification each employee has an e-mail address provided by the company.

5. Uploading training materials and tests related to each training material.

6. Generating the training topics for each worker directly from the application based on the uploaded instructions.

7. Sending training materials and tests to each worker at the e-mail address provided by the company.

8. The effective training of the workers consisted in them receiving a link to access the ssm.ro platform on the email address. Once the account was created they had access to all training and testing materials and after fully completing them, they proceeded to the electronic signing of the document attesting the completion of the training and testing materials.

9. The supervisor was automatically informed by the platform that his / her subordinates had completed the training and testing, including the electronic signing of the form, which in turn entitles him / her to sign the training performed as supervisor.

10. After the supervisor signs the occupational health and safety form in electronic format, the platform ensures the automatic transmission of the training file to the person designated by the employer to verify and certify the training process by electronic signature.

By completing the 10 steps, the employer can prove the fulfillment of the obligations provided by law regarding the training of workers.

The data on the use of the online training and management platform "ssm.ro" used in this study are presented in table 1 and figures 1 and 2 .

Table 1. The data used on the online platform "ssm.ro" in the training process of the employees.

\begin{tabular}{|l|c|c|c|c|c|}
\hline Company & $\begin{array}{c}\text { Trained } \\
\text { employees }\end{array}$ & $\begin{array}{c}\text { Loaded } \\
\text { training } \\
\text { materials }\end{array}$ & $\begin{array}{c}\text { OSHA files } \\
\text { gerenated }\end{array}$ & $\begin{array}{c}\text { Departaments } \\
\text { created }\end{array}$ & $\begin{array}{c}\text { Generated } \\
\text { electronic } \\
\text { signatures }\end{array}$ \\
\hline I & 97 & 9 & 97 & 4 & 300 \\
\hline O & 384 & 18 & 384 & 10 & 1170 \\
\hline Total & 481 & 27 & 481 & 14 & 1470 \\
\hline
\end{tabular}

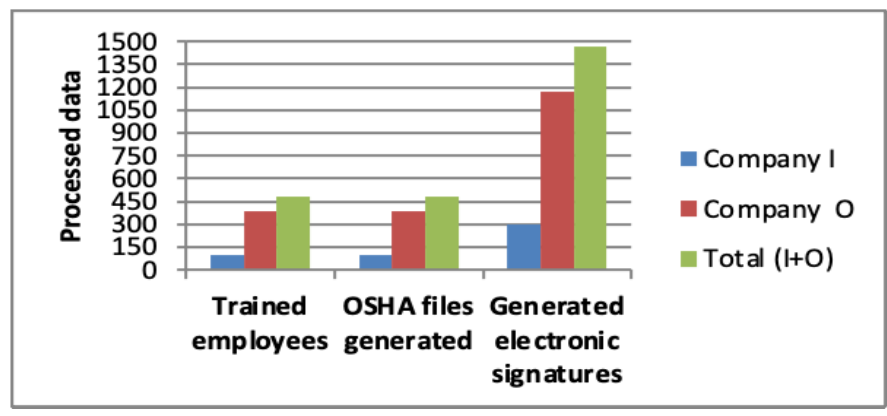

Fig. 1. The data on the use of the online platform "ssm.ro" in the training process of employees of companies "I" and "O" (Trained employees, OSHA files generated and Generated electronic signatures). 


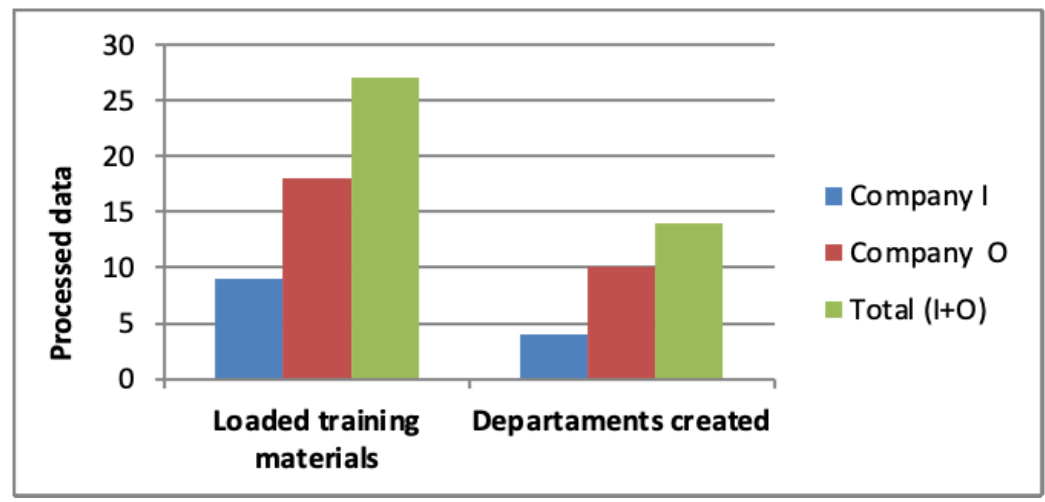

Fig. 2. Data on the use of the online platform "ssm.ro" in the training process of employees of companies "I" and "O" (Loaded training materials and Departments created).

During the pandemic, firms requested companies working in the field of occupational safety to come up with viable solutions so that their employees could undergo the necessary training for the work from home. As this happened very quickly, companies as well as external services with which companies had and have occupational health services contracts have been put to the test due to the fact that the legislation in the field clearly specifies that we must have proof of training and this must be recorded manually in the occupational health and safety data sheets!

\section{Discussion}

The transition to the online environment and implicitly in order to have the possibility to perform the Occupational Health and Safety activity in compliance with the legal provisions, taking into account a large number of consultations with the factors involved in occupational health and safety, below you can find the proposal to supplement GD 1425/2006 in which we inserted the amendment that gives the possibility to digitize the occupational health and safety activity, taking into account the possibilities currently existing from an IT and legal point of view.

Article 81

(1) The result of the occupational health and safety training of the workers is mandatorily recorded in the individual training record, according to the sample presented in annex no. 11, on paper or in electronic format, specifying the material taught, the duration and date of the training.

(2) The individual training record shall be filled in with an ink pen or ballpoint pen, immediately after the training verification.

(3) After the training, the individual training record is signed by the trained worker and by the persons who performed and verified the training, handwritten, if the record is prepared in hard copy, or with advanced electronic signature, if it is in electronic format, accompanied by the electronic time stamp.

(4) The individual training record shall be kept, in hard copy or in electronic format, by the employer and shall be accompanied by a copy of the last "fit to work" certificate completed by the labor doctor, in hard copy or in electronic format accompanied by the electronic time stamp. 


\section{Conclusions}

The large number of requests from companies that intend to use work from home, teleworking and more, and who want to use the online environment to ensure compliance with occupational health and safety obligations clearly leads to the need to find solutions for managing the activity in the environment online.

\section{References}

1. Activity Report of Brasov Territorial Labour Inspectorate, (2019) http://www.itmbrasov.ro, [Accessed 08.05.2020]

2. A. Barkhordari, B. Malmir, M. Malakoutikhah, SH@W, 10, 205 (2019)

3. D.J. Wilson, K. Takahashi, S. Sakuragi, M. Yoshino, T. Hoshuyama, T. Imai, J. Takala, JOH 49, 72 (2007)

4. P.E. Spector, J. Occup. Psychol., 61, 335 (1988)

5. https://eur-lex.europa.eu/legal-content/en/TXT/?uri=CELEX\%3A52016DC0179, [Accessed 08.05.2020]

6. https://www.who.int/occupational_health/who_workers_health_web.pdf, [Accessed 08.05. 2020.

7. R.D. Moran, WMLR, 15, 777 (1974)

8. Y. Kim, J. Park, M. Park, SH@W, 7, 89, (2016)

9. http://www.who.int/occupational_health/publications/launch_hwp_22april.pdf, [Accessed 08.05.2020] 